\title{
A case story, involving the use of maltitol, a sugar alcohol, as a cutting agent in amphetamine and cocaine powders
}

\author{
Lotte Ask Reitzel*, Niels Bjerre Holm, Kristian Linnet and Irene Breum Müller
}

Section of Forensic Chemistry, Department of Forensic Medicine, Faculty of Health and Medical Sciences, University of Copenhagen, Frederik V's Vej 11, 3, DK-2100, Copenhagen, Denmark

* lotte.reitzel@sund.ku.dk

\begin{abstract}
:
In a criminal case involving cutting and resale of amphetamine and cocaine in the Copenhagen area of Denmark, maltitol was used as a cutting agent. The analysis of maltitol in seizures of pure diluents as well as in amphetamine and cocaine powders was carried out using reversed-phase high performance liquid chromatography (HPLC) with high-resolution (HR) mass spectrometric detection. Maltitol was identified in four out of nine amphetamine samples and in five out of six cocaine samples from the case in question. The use of maltitol as a cutting agent was considered by the police as a specific marker of the particular criminal group under investigation. To support or reject this hypothesis, cocaine and amphetamine samples from a four month period after the involved persons had been arrested were evaluated, also as part of the police investigation. None of these samples contained maltitol. The work described covers the part of the case involving the department of forensic chemistry, and not the whole police investigation, but everything was done within the frames given by the police. To the best of our knowledge, this is the first report of a disaccharide polyol being used as a cutting agent for illicit drugs.

Keywords:

Maltitol, sugar alcohol, mass spectrometry, cutting agent, illicit drugs, polyols
\end{abstract}

\begin{abstract}
Abbreviations:DDA:Data-dependent acquisition, ESI:Electrospray ionization, HR: High-resolution, HPLC: High-performance liquid chromatography, RT: Retention time, GC-MS: Gas chromatography-mass spectrometry, DAD: Diode array detection, FID: Flame ionization detection
\end{abstract}

\section{INTRODUCTION}

Illicit drugs like amphetamine and cocaine are most often diluted with one or more compounds referred to as cutting agents. In Denmark, the purity of amphetamine at street level were in the range $1-76 \%$ (mean: $9 \%$, median: $5 \%$ ) in 2013 and $2-74 \%$ (mean: $20 \%$, median: $14 \%$ ) in 2014, and that of cocaine were in the range 2 - $78 \%$ (mean: 29\%, median: $25 \%$ ) in 2013 and $<1-86 \%$ (mean: $30 \%$, median: $22 \%$ ) in $2014[1,2]$.

The sugars and sugar alcohols previously reported as cutting agents are the monosaccharides glucose [3-7] and fructose [3], the disaccharides lactose/maltose and sucrose [3-6], and the monosaccharide sugar alcohols mannitol [3-6]and inositol [3,5-6]. During the investigation of a large case (See section "Case description") involving seizures of illicit drugs and cutting agents in the Copenhagen area of Denmark, the sugar alcohol maltitol was used for dilution of amphetamine and cocaine powders.

Maltitol, 4-O-a-D-Glucopyranosyl-D-sorbitol, is derived from the hydrogenation of maltose obtained from starch, making maltitol a 12-carbon sugar alcohol, also called a disaccharide polyol. Many sugars and sugar alcohols are stereo- or positional isomers, and for maltitol known isomers are the stereoisomer lactitol, 4-O- $\beta$-D-Glucopyranosyl-D-sorbitol, and the positional isomers and components of isomalt, 6-O-a-D-glucopyranosyl-Dsorbitol (GPS), also known as isomaltitol, and 6-O-a-D-glucopyranosyl-Dmannitol (GPM) $[8,9]$.
Maltitol is commonly used as a sugar substitute and also as an excipient by the pharmaceutical industry [8-11], but hitherto the use of a disaccharide polyol as a cutting agent for illicit drugs has not been reported. Cutting agents can be important from a toxicological point of view, but also for intelligence purposes, and as such cutting agents have been used as marker compounds for the comparison of various street samples $[12,13]$.

Sugars and sugar alcohols in pure powders can be analyzed by spectroscopic techniques such as infrared spectroscopy (IR), Raman and NMR. Raman spectra for maltitol, lactitol and isomaltitol have been published [14] and can be distinguished, at least for the pure compounds. The disadvantage of these kinds of techniques is that they provide no separation of compounds, making chromatographic methods more appropriate for the analysis of illicit drugs that are diluted with a mixture of cutting agents. Thus, chromatographic analysis of sugar diluents in illicit drugs can be performed by gas chromatography-mass spectrometry (GCMS) $[15,16]$, but this requires derivatization due to the polar nature of the compounds, making the process cumbersome. Alternatively, sugar diluents have been directly analyzed by liquid chromatography with e.g. refractive index (RI) detection [3] or with high $\mathrm{pH}$ anion exchange chromatography coupled to pulsed amperometric detection [8] or even mass spectrometric detection (MS) with the insertion of a desalter between the column and the detector [17]. The high $\mathrm{pH}$ anion exchange chromatography effectively separates maltitol, lactitol and isomaltitol.

In the present case we turned towards in-house equipment and methods, since it was important that an analytical method was set up quickly, as the results were to be used in the on-going police investigation. High-performance liquid chromatography (HPLC) and high-resolution (HR) mass spectrometry were successfully applied for the analysis of maltitol in the samples from the present case as well as other seized materials. 


\section{CASE DESCRIPTION}

The presented work was done as part of a Danish police investigation on a case involving cutting and resale of amphetamine and cocaine in the Copenhagen area of Denmark. Samples of 19 white to off-white powders were sent to our department for analysis during the investigation.

The first powder received at our department was, by the police, suspected to be from a product called Maltidex ${ }^{\mathrm{TM}}$ manufactured by the company "Cargill", as the suspects in the case had been seen carrying large bags, marked with this brand into an apartment building (a production site). At a subsequent raid on the site, the police found similar, emptied Cargill bags. The powder in question was sampled from one of these bags. The ingredient of Maltidex ${ }^{\mathrm{TM}}$ is maltitol (Fig. 1A, insert). The powder could not be identified in our routine screenings, nor in additional tests for sugars (Fehling's reaction) and starch (lodine coloring and microscopy), but was confirmed to be maltitol by NMR and mass spectrometry (data not shown).

The 18 other powders ( 9 amphetamine, 6 cocaine, and 3 cutting agent) were analyzed by HPLC-HR-MS in order to see if they also contained maltitol.

Approximately half a year after the suspects had been arrested and thus supposedly were no longer active, the police asked for additional maltitol analyses of 10 amphetamine powders and 10 cocaine powders, randomly chosen from various new and supposedly independent cases in Eastern Denmark (incl. Copenhagen). The aim was to test their hypothesis that the use of maltitol as a cutting agent in illicit drugs was specific to the present case.

\section{MATERIALS AND METHODS}

\subsection{Chemicals}

LC-MS grade methanol and water were from Fisher Scientific (Leicestershire, UK). Ammonium formate and formic acid were purchased from Merck (Darmstadt, Germany). Maltitol (4-O-a-D-Glucopyranosyl-D-sorbitol), D-lactitol monohydrate (4-O- $\beta$-D-Galactopyranosyl-D-sorbitol) and isomaltitol (6-O-a-D-Glucopyranosyl-D-sorbitol) were purchased from Sigma-Aldrich (St. Louis, MO, USA).

\subsection{Selection of seized powders}

During the police investigation we received 19 samples of seized powders from the case in the period from April to December 2013.

In the beginning of 2014 we were asked to select 10 amphetamine and 10 cocaine samples from other cases (We did not select 10 of each, but 6 and 11 , respectively). The samples in our storage were from the period 29 10-2013 - 12-03-2014, and included 22 cocaine cases with 73 samples and 23 amphetamine cases with 55 samples. All samples were from Eastern Denmark, including Copenhagen.

In order to select samples from these other cases, the purity of active compound was considered and the amount of other identified cutting agents were assessed by visual inspection of the existing chromatograms from the routine analyses in order to evaluate if it was likely that an unidentified cutting agent was present. Based on this evaluation 11 cocaine cases and 17 amphetamine cases were omitted, as it was found unlikely that any unidentified cutting agent could be present, leaving 11 cocaine cases with
19 samples and a median of 2 samples per case and 6 amphetamine cases with 16 samples and a median of 1 sample per case. When a case contained multiple samples, only one sample was selected. In this way it was possible to reasonably select samples within the frames of the investigation, and the final selection of samples from other cases included 11 cocaine samples and 6 amphetamine samples. The purity range for the cocaine samples were 10 - $49 \%$. 2 of the cocaine samples contained no identified cutting agents, 3 contained only small amounts of levamisole, and 6 contained a mixture of 2-3 of the compounds levamisole, phenacetine, caffeine and lidocaine, but still with possible room for an unidentified cutting agent. The purity range for the 6 amphetamine samples were $3-25 \% .5$ of the amphetamine samples contained no identified cutting agents, and one contained some creatine.

\subsection{Sample preparation}

Seized powders were dissolved to a nominal concentration of $1.0 \mathrm{mg} / \mathrm{ml}$ in $25 \% \mathrm{v} / \mathrm{v}$ methanol:1\% formic acid in water. The solutions were subsequently filtered through a $0.50 \mu \mathrm{m}$ membrane (Advantec MFS, Dublin, CA, USA) and further diluted 100 -fold with $25 \% \mathrm{v} / \mathrm{v}$ methanol:1\% formic acid in water containing cyclobarbital $(1 \mu \mathrm{g} / \mathrm{ml})$ and mianserin $(1 \mu \mathrm{g} / \mathrm{ml})$ as internal standards for negative and positive ESI mode, respectively. Reference standards were initially dissolved to $1.0 \mathrm{mg} / \mathrm{ml}$ in water, and then diluted as described for the seized powders.

\subsection{Routine screening and quantification}

Currently, we initially screen all seized powders, tablets etc. by GC-MS. If no illicit drugs are identified, a HPLC-DAD screening is also performed. Cocaine and amphetamine are subsequently quantified by GC-FID, and HPLC-DAD, respectively. These methods are validated and accredited in accordance with the requirements of the DS/EN ISO/IEC 17025 standard. Most adulterants will be identified in the GC-MS screening, while creatine will give a signal in the HPLC-DAD analysis. However, a number of compounds, such as sugars, sugar alcohols including maltitol, starch, and inorganic compounds will not be detected in these routine analyses.

\subsection{HPLC-HR-MS}

The chromatography was carried out on a $3 \mu \mathrm{m}$ Hypersil Gold PFP (150 mm x $2.1 \mathrm{~mm}$ ) column (Thermo Scientific, CA, USA) maintained at $40^{\circ} \mathrm{C}$ using a Dionex Ultimate 3000 UHPLC system (Thermo Scientific, Germering, Germany). The mobile phase consisted of solvent A (water containing $10 \mathrm{mM}$ ammonium formate and $0.1 \% \mathrm{v} / \mathrm{v}$ formic acid, adjusted to $\mathrm{pH}=3.0$ ) and $\mathrm{B}$ (methanol and $0.1 \% \mathrm{v} / \mathrm{v}$ formic acid). The gradient started at $5 \% \mathrm{~B}$ increasing to $95 \%$ B over $10 \mathrm{~min}$, isocratic for $1 \mathrm{~min}$ and $3 \mathrm{~min}$ for re-equilibration. The flow rate was $0.3 \mathrm{ml} / \mathrm{min}$. The injection volume was $2.5 \mu \mathrm{l}$. The high-resolution Q-Exactive mass spectrometer (Thermo Scientific, Bremen, Germany) was operated with negative electrospray ionization (-ESI) in data-dependent acquisition (DDA) mode. Full and $\mathrm{MS}^{2}$ scans were acquired at a resolution of 70.000 and 17.500 (Full width at half maximum at $m / z=200$ ), respectively. The higher-energy collisional dissociation energy was 25 . The mass accuracy was within $5 \mathrm{ppm}$. RT and $\mathrm{MS}^{2}$ spectrum were recorded for each reference standard $(0.01 \mathrm{mg} / \mathrm{ml})$. The linear range for maltitol was determined by serial dilutions in water at $0.1,0.05,0.01,0.050,0.0025,0.001$, and 0.0001 
$\mathrm{mg} / \mathrm{ml}$, and the absolute peak areas were fitted using a linear fit with a $1 / \mathrm{x}$ weighting. A system control of maltitol was run before and after each batch of samples to ensure stable peak areas. The figure was made, using RStudio (RStudio, Inc., Boston, MA, USA).

\section{RESULTS}

\subsection{Detection of maltitol}

The [M-H] adduct of maltitol at $\mathrm{m} / \mathrm{z} 343.1246$ could be detected at 0.0001 $\mathrm{mg} / \mathrm{ml}$, the lowest concentration level tested. The peak areas showed good linearity in the range $0.0001 \mathrm{mg} / \mathrm{ml}$ to $0.01 \mathrm{mg} / \mathrm{ml}$, which would correspond

to a maltitol content in the powder of $1 \% \mathrm{w} / \mathrm{w}$ and $100 \% \mathrm{w} / \mathrm{w}$, respectively. The chromatography could not resolve maltitol, lactitol, and isomaltitol (Table 1), which also showed indistinguishable fragmentation patterns (data not shown). The disaccharides lactose, maltose and sucrose also co-eluted, but could be distinguished from the investigated sugar alcohols based on exact masses and fragment ions (Table 1). Fig. 1 A shows the $\mathrm{MS}^{2}$ scan of the maltitol reference standard, and Fig. 1B that of an amphetamine sample.

\subsection{Analysis of illicit powders}

A total of 36 illicit powders were analyzed. 19 of these samples were from the case and included 4 samples of maltitol, 5 amphetamine samples of $8-20 \%$

Table 1. Data for sugar alcohols and disaccharides investigated

\begin{tabular}{|c|c|c|c|c|}
\hline Compound & $\begin{array}{c}\mathrm{RT} \\
(\mathrm{min})\end{array}$ & $\begin{array}{c}\text { Elemental } \\
\text { composition, } \mathrm{M}\end{array}$ & $\begin{array}{c}\text { Monoisotopic mass, } \\
{[\mathrm{M}-\mathrm{H}]^{-}(\mathrm{m} / \mathrm{z})}\end{array}$ & 343.1246 \\
\hline Lactitol & 1.45 & $\mathrm{C}_{12} \mathrm{H}_{24} \mathrm{O}_{11}$ & 343.1246 \\
\hline Maltitol & 1.46 & $\mathrm{C}_{12} \mathrm{H}_{24} \mathrm{O}_{11}$ & 343.1246 \\
\hline Isomaltitol & 1.48 & $\mathrm{C}_{12} \mathrm{H}_{24} \mathrm{O}_{12}$ & 341.1089 \\
\hline Lactose & 1.45 & $\mathrm{C}_{12} \mathrm{H}_{22} \mathrm{O}_{11}$ & $89.0231,119.0339,179.0552$ \\
\hline Maltose & 1.48 & $\mathrm{C}_{12} \mathrm{H}_{22} \mathrm{O}_{11}$ & 341.1089 \\
\hline Sucrose & 1.50 & $\mathrm{C}_{12} \mathrm{H}_{22} \mathrm{O}_{11}$ & $39.0231,119.0339,179.0552$ \\
\hline
\end{tabular}

\section{A) Maltitol reference standard}

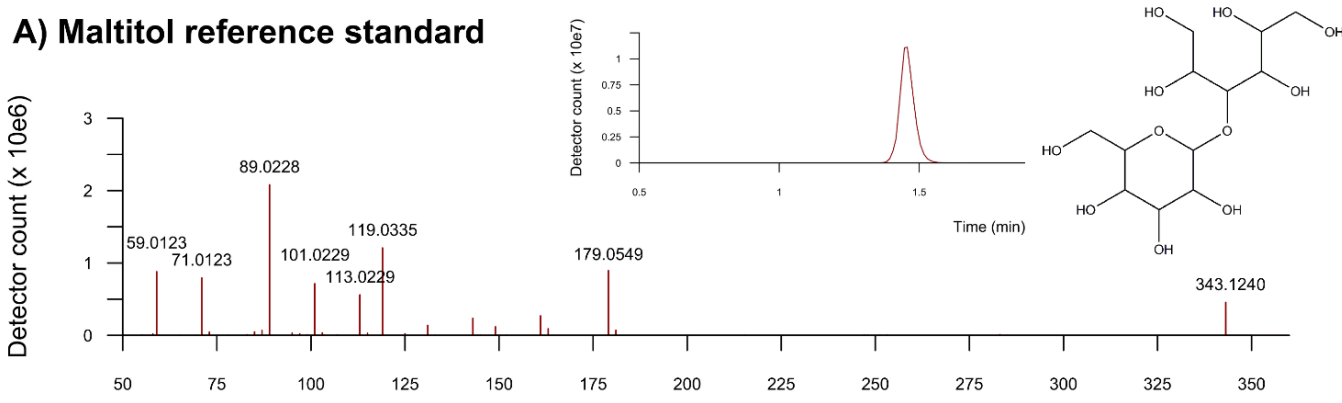

\section{B) Seized sample}

Figure 1. Extracted ion chromatogram (EIC) and $\mathrm{MS}^{2}$ spectrum of maltitol from A) reference standard and B) a seized sample 
.

purity without maltitol, 4 amphetamine samples of $2-7 \%$ purity diluted with maltitol, 1 cocaine sample of $65 \%$ purity without maltitol, and 5 cocaine samples of $19-24 \%$ purity diluted with maltitol (Table 2 ). In the selection of 11 cocaine samples and 6 amphetamine samples from independent cases no maltitol was present.

Table 2. Samples from the case (2013)

\begin{tabular}{|c|c|c|c|}
\hline Controlled substance & Maltitol present & No. of samples & $\begin{array}{c}\text { Purity }(\% \mathrm{w} / \mathrm{w}) \text { of the } \\
\text { controlled substance }\end{array}$ \\
\hline Amphetamine & No & 5 & $8-20$ \\
\hline & Yes & 4 & $2-7$ \\
\hline Cocaine & No & 1 & 65 \\
\hline & Yes & 5 & $19-24$ \\
\hline None & No & 0 & - \\
\hline & Yes & 4 & - \\
\hline
\end{tabular}

The additional information from the police about cutting agent originating from Cargill Maltidex ${ }^{\mathrm{TM}}$ bags strongly suggests that, even though the applied analytical method cannot discriminate between maltitol and its stereo- and positional isomers, the diluent in this case is indeed maltitol based on the combined lines of evidence.

Other observed cutting agents in amphetamine samples from the case were caffeine, creatine, or a mixture of these. These are in general the most frequently observed cutting agents in the amphetamine samples seized in Denmark [1,2]. In cocaine samples from the case the other observed cutting agents were caffeine, a mixture of caffeine and lidocaine, or a mixture of lidocaine and levamisole. While phenacetin and levamisole overall is the most frequently observed cutting agents in the cocaine samples seized in Denmark [1,2], phenacetin was completely absent in the case samples.

\section{DISCUSSION AND CONCLUSION}

The applied chromatography was initially developed for analysis of basic drugs of abuse using positive ESI. The use of negative ESI in the beginning of the chromatography allowed for simultaneous screening of sugars and sugar alcohols in the same run. The method presented here is adequately sensitive for maltitol, but cannot discriminate between maltitol and its stereo- and positional isomers. However, the police investigation supplied complementary evidence that maltitol, and not an isomer, was used for cutting. Therefore, the detection of disaccharide polyols in samples from the case is interpreted as maltitol based on the combined evidence, and reported as such for use in the police investigation as well as in court.

The results from the case show that the more diluted amphetamine and cocaine samples contained maltitol, while the less diluted did not (Table 2), consistent with the idea that maltitol had been added to the drug powders in Denmark. None of the analyzed samples from the selected 11 cocaine and 6 amphetamine cases from ultimo 2013 to primo 2014, supposed to be independent cases, contained maltitol. For the other 11 cocaine and 17 amphetamine cases from ultimo 2013 to primo 2014 the same conclusion was tentatively drawn by process of elimination based on evaluation of GC-MS and HPLC-DAD chromatograms with respect to presence of detectable diluents, and on quantitative results from the routine analyses. Thus, all cocaine and amphetamine samples from the period were assessed. This indicates that use of maltitol as a cutting agent in cocaine and amphetamine in Eastern Denmark is, at least relatively rare. However in general, maltitol is still not covered by routine analyses in forensic laboratories.

In conclusion, we present here a case of a disaccharide polyol being used as a cutting agent in cocaine and amphetamine powders. The use of maltitol appeared to be specific to a particular criminal group, since the presence of maltitol in illicit drugs has not been previously reported, and since no maltitol was detected in samples from a four months period subsequent to the arrest of the group members. As such, the presence of maltitol in cocaine and amphetamine was used by the police as a fingerprint for that specific criminal group. Furthermore, it was used as evidence of the group's intention to cut and resale more drugs, since pure maltitol was also seized.

\section{Conflict of interest: None}

\section{REFERENCES}

[1] Lindholst C., Müller I.B., Faurskov B., Christoffersen D., Worm-Leonhard M., Lindal L., Reitzel L.A., Nissen H., Johannsen M., Drugs at street level 2013, Report to the Danish Board of Health, 2014 (In Danish, Narkotika på gadeplan 2013, accessed 2016-03-31 at: https://sundhedsstyrelsen.dk/da/sundhed/narkotika/ / media/15E21ED8275B4ED68A50AC0E5A9CC4AD.ashx)

[2] Lindholst C., Müller I.B., Faurskov B., Christoffersen D., Worm-Leonhard M., Lindal L., Reitzel L.A., Nissen H., Johannsen M., Drugs at street level 2014, Report to the Danish Board of Health, 2015 (In Danish, Narkotika på gadeplan 2014, accessed 2016-03-31 at: https://sundhedsstyrelsen.dk/da/sundhed-og-livsstil/ narkotika/ /media/E4B47C18F5DD49EDAA894C59A58D11EC.ashx)

[3] Andreasen M.F., Lindholst C., Kaa E., Adulterants and Diluents in Heroin, Amphetamine, and Cocaine Found on the Illicit Drug Market in Aarhus, Denmark, The Open Forensic Sci. J., 2009, 2, 16-20

[4] Cole C., Jones L., Mcveigh J., Kicman A., Syed Q., Bellis M., Adulterants in illicit drugs: a review of empirical evidence, Drug Test. Anal., 2011, 3, 89-96
[5] Cunningham E.E., Venuto R.C., Zielezny M.A., Adulterants in heroin/cocaine: Implications concerning heroin-associated nephropathy, Drug and Alcohol Depend., 1984, 14, 19-22

[6] Lurie I., Hays P., Valentino A., Analysis of Carbohydrates in Seized Heroin Using Capillary Electrophoresis, J Forensic Sci, 2006, 51, 39-44

[7] King L.A., Drug content of powders and other illicit preparations in the UK, Forensic Sci. J., 1997, 85, 135-147

[8] Cataldi T.R.I., Campa C., Casella I.G., Bufo S.A., Anion-Exchange Chromatography with Pulsed Amperometric Detection, J. Agric. Food Chem., 1999, 47, 157-163

[9] Dills W.L., Sugar alcohols as bulk sweeteners, Annu. Rev. Nutr., 1989, 9, 161-186

[10] EPA, European Association of Polyol Producers: http://www.polyols-eu.com/. Accessed 2015-09-04.

[11] Ghosh S., Sudha M.L., A review on polyols: new frontiers for health-based bakery products, Int. J. Food Sci. Nutr., 2012, 63, 372-379 
[12] Maietti S., Castagna F., Molin L., Ferrara S.D., Traldi P., Cocaine adulterants used as marker compounds, J. Mass Spectrom., 2009, 44, 1124-1126

[13] Terrettaz-Zuffrey A.-L., Ratle F., Ribaux O., Esseiva P. Kanevski M., Pattern detection in forensic case data using graph theory: Application to heroin cutting agents, Forensic Sci. Int., 2007, 167, 242-246

[14] De Veij M., Vandenabeele P., De Beer T., Remon J.P., Moens L., Reference database of Raman spectra of pharmaceutical excipients, J. Raman Spectrosc., 2009, 40, 297-307

[15] Lociciro S., Hayoz P., Esseiva P., Dujourdy L., Besacier F., Margot P., Cocaine profiling for strategic intelligence purposes, a cross-border project between France and Switzerland Part I. Optimisation and harmonisation of the profiling method, Forensic Sci. Int., 2007, 167, 220-228

[16] Baer I., Margot P., Sugar and fatty acid analysis in ecstasy tablets, Forensic Sci. Int., 2007, 167, 229-233

[17] Lopez L., Wang L., Zheng T., Tracy M., Corpuz R., Slingsby R., Analysis of Carbohydrates and Lipids in Microalgal Biomass with HPAE-MS and LC/MS, Dionex Corporation, Sunnyvale, CA, 2009 